\title{
Evidence for a role of nitric oxide in hindlimb vasodilation induced by hypothalamic stimulation in anesthetized rats
}

\author{
MARCOS L. FERREIRA-NETO, OLGA S. POSSAS, OSWALDO U. LOPES and SÉRgIO L. CRAVO \\ Departamento de Fisiologia, Disciplina de Fisiologia Cardiovascular e Respiratória, UNIFESP-EPM \\ Rua Botucatu, 862, 04023-060 São Paulo, SP, Brasil
}

Manuscript received on July 26, 2004; accepted for publication on November 24, 2004;

contributed by OsWALDO U. LOPES*

\begin{abstract}
Electrical stimulation of the hypothalamus produces cardiovascular adjustments consisting of hypertension, tachycardia, visceral vasoconstriction and hindlimb vasodilation. Previous studies have demonstrated that hindlimb vasodilation is due a reduction of sympathetic vasoconstrictor tone and to activation of $\beta_{2}$-adrenergic receptors by catecholamine release. However, the existence of a yet unidentified vasodilator mechanism has also been proposed. Recent studies have suggested that nitric oxide (NO) may be involved. The aim of the present study was to investigate the role of NO in the hindquarter vasodilation in response to hypothalamic stimulation. In pentobarbital-anesthetized rats hypothalamic stimulation $(100 \mathrm{~Hz}, 150 \mu \mathrm{A}, 6 \mathrm{~s})$ produced hypertension, tachycardia, hindquarter vasodilation and mesenteric vasoconstriction. Alpha-adrenoceptor blockade with phentolamine $(1.5 \mathrm{mg} / \mathrm{kg}$, iv) plus bilateral adrenalectomy did not modify hypertension, tachycardia or mesenteric vasoconstriction induced by hypothalamic stimulation. Hindquarter vasodilation was strongly reduced but not abolished. The remaining vasodilation was completely abolished after iv injection of the NOS inhibitor L-NAME (20 mg/kg, iv). To properly evaluate the role of the mechanism of NO in hindquarter vasodilation, in a second group of animals L-NAME was administered before $\alpha$-adrenoceptor blockade plus adrenalectomy. L-NAME treatment strongly reduced hindquarter vasodilation in magnitude and duration. These results suggest that NO is involved in the hindquarter vasodilation produced by hypothalamic stimulation.
\end{abstract}

Key words: hindlimb blood flow, hypothalamus, electrical stimulation, defense reaction.

\section{INTRODUCTION}

Defense reactions are a broad class of behaviors observed in numerous mammalian species, including man (Azevedo et al. 1980, Smith and Woodruff 1980, Bolme et al. 1967) and comprise speciesdistinctive adjustments both in motor and neurovegetative output (Abrahams et al. 1964, Feigl et al. 1964, Hilton and Zbrozyna 1963, Abrahams et al.

*Member Academia Brasileira de Ciências

Correspondence to: Marcos L. Ferreira-Neto

E-mail: marcosneto@fcr.epm.br 1960a, Eliasson et al. 1951). The neurovegetative adjustments include cardiovascular, respiratory and endocrine changes that support the increased metabolic demand during fight or flight responses.

Cardiovascular adjustments seen during defense reactions include hypertension, tachycardia and muscle vasodilation. Since the defense reaction generally involves intense motor activation, muscle vasodilation is regarded as a key feature of these responses. However, the mechanisms and central pathways involved in this vasodilation remain un- 
clear. At least three different mechanisms have been proposed: a. reduced sympathetic vasoconstrictor drive; b. release of catecholamines by the adrenal medulla, and c. activation of a sympathetic vasodilator system.

Whereas in the dog and cat the existence of a cholinergic sympathetic vasodilator system is well established (Timms 1981, Schramm et al. 1971, Bolme et al. 1967, Abrahams et al. 1960a, b), there is no evidence for such a mechanism in others species including the rabbit, the monkey and the rat.

Recently, several lines of evidence have suggested that nitric oxide (NO) and/or nitrosylated factors (NOFs) may act as neurotransmitters involved in hindlimb vasodilation. First, the lumbar sympathetic chain contains postganglionic sympathetic fibers immunopositive for nitric oxide synthase (NOS) (Davisson et al. 1994). Second electrical stimulation of post-ganglionic fibers in the lumbar sympathetic chain produces hindlimb vasodilation that is dependent on NO synthesis (Davisson et al. 1997). Third, these fibers may be involved in the hindlimb vasodilation observed in responses to baroreceptor stimulation (Possas and Lewis 1997). They may also be involved in defense reactions elicited by air jet stress (Davisson et al. 1994).

Therefore in the present study we sought to investigate the possible role of $\mathrm{NO}$ during the hindlimb vasodilation induced by electrical stimulation of hypothalamic sites in anesthetized rats.

\section{MATERIALS AND METHODS}

\section{General Procedures}

Male Wistar rats (250-350 g body wt) were obtained from the central animal house of the Universidade Federal de São Paulo - Escola Paulista de Medicina. All protocols describe here were approved by the Medical Ethics Committee of the Universidade Federal de São Paulo.

Anesthesia was induced with $2 \%$ halothane in $100 \% \mathrm{O}_{2}$ and catheters were placed into the right carotid artery and jugular vein for measurement of arterial blood pressure and heart rate and admin- istration of drugs, respectively. Once the venous catheter was in place, the animals were anesthetized with pentobarbital sodium ( $40 \mathrm{mg} / \mathrm{kg}$ iv). The anesthetic was supplemented (4 mg/kg iv) every $30 \mathrm{~min}$ for the remainder of the experiment. The arterial catheter was connected to a pressure transducer attached to a bridge amplifier (ETH-200, CB Sciences, Inc) to record arterial pressure. Pulsatile (AP) and mean (MAP) arterial blood pressure, heart rate (HR), mesenteric (MBF) and hindquarter blood flows (HQBF) were recorded continuously with a PowerLab system (ADInstruments). Heart rate was determined from the AP signal. The trachea was cannulated to reduce airway resistance, and the rats were mounted prone in a stereotaxic apparatus (David Kopf Instruments) with the bite bar set $3.4 \mathrm{~mm}$ below the interaural line. Infusion $(1 \mathrm{ml} / \mathrm{hr})$ of bicarbonate, dextrose and dextran in saline (Quintin et al. 1989) was maintained throughout the experiment. Body temperature was maintained at $37 \pm 0.5^{\circ} \mathrm{C}$ with a thermostatically controlled heating table.

Blood Flow Recording: Miniature pulsed Doppler flow probes (Haywood et al. 1981) were placed on the superior mesenteric artery and the inferior abdominal aorta for the measurement of mesenteric and hindquarter blood flows and for the determination of vascular conductance.

Hypothalamic Stimulation (HS): A dorsal craniotomy was performed and a Teflon-coated tungsten microelectrode advanced to the hypothalamus. Stimulation sites were located within 3.3 to $4.3 \mathrm{~mm}$ caudal, $1.5 \mathrm{~mm}$ lateral, and 7.5 to $8.5 \mathrm{~mm}$ ventral in relation to the bregma (Paxinos and Watson 1986), a region corresponding to the defense area in the rat (Tan and Dampney 1983, Yardley and Hilton 1986, 1987). The hypothalamus was electrically stimulated for 6 seconds with cathodal square wave pulses $(150 \mu \mathrm{A}, 0.5 \mathrm{~ms}, 100 \mathrm{~Hz})$ obtained from a Grass S88 stimulator through a PSIU6 isolation unit. Sufficient time ( $\geq 10 \mathrm{~min}$ ) was allowed between stimuli to permit the hemodynamic parameters to return to control values. 
Adrenalectomy: The adrenal glands were accessed through left and right retroperitoneal approaches. The glands were freed from surrounding tissue and removed after the adrenal arteries and veins had been ligated.

Histology: Electrolytic lesions (1 mA DC for $15 \mathrm{~s}$ ) were made in the hypothalamus at the end of all experiments; the animals were perfused transcardially with $10 \%$ formalin and the brains were removed. The hypothalamus was cut coronally into $40 \mu \mathrm{m}$ thick sections and stained with $1 \%$ neutral red. Sections containing the lesion were examined and plotted on drawings adapted from a rat stereotaxic atlas (Paxinos and Watson 1986) with the aid of a camera lucida attachment (Nikon). A typical site of hypothalamic stimulation is shown in Fig. 1.

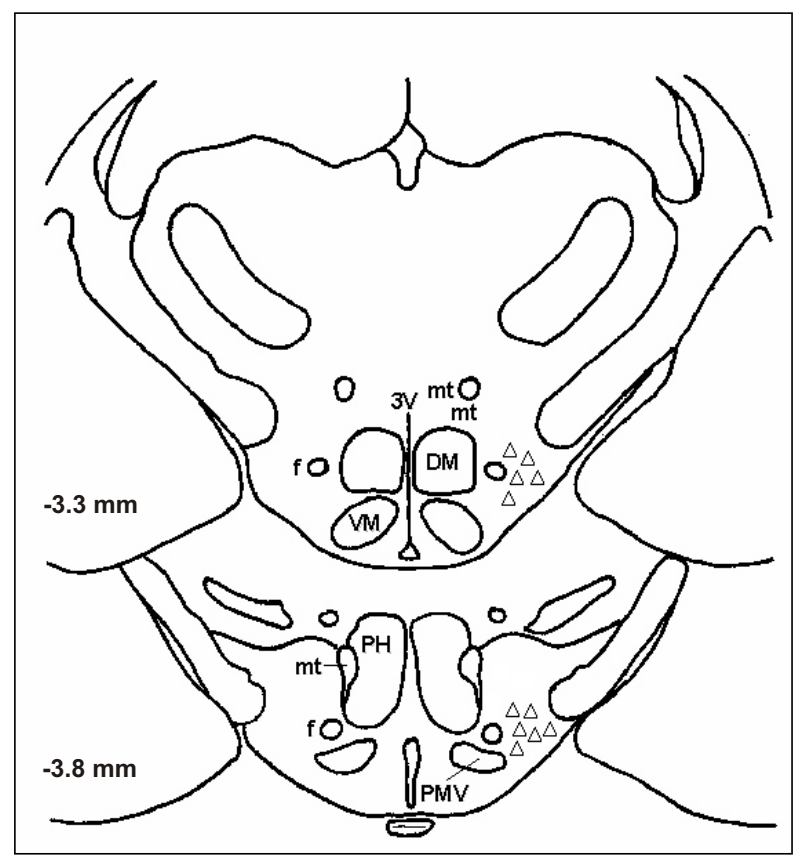

Fig. 1 - Distribution of stimulation sites in the hypothalamus (triangles): Abbreviations: $\mathbf{m t}$, mammillothalamic tract; $\mathbf{3 V}, 3^{\text {rd }}$ ventricle; f, fornix; DM, dorsomedial hypoth. nu.; VM, ventromedial hypoth. nu.; PH, posterior hypothalamus area. Numbers to the left of each diagram represent the approximate distance posterior to the bregma.

Drugs: The drugs used were phentolamine $\left(1.5 \mathrm{mg} / \mathrm{kg}\right.$, iv) and $N^{\omega}$-nitro-L-arginine methyl ester (L-NAME; $20 \mathrm{mg} / \mathrm{kg}$, iv) purchased from Sigma
Chemical Company (St. Louis, MO). Drugs were dissolved in sterile saline and the $\mathrm{pH}$ was adjusted to 7.4 .

Data Analysis: Mesenteric (MVC) and hindquarter relative vascular conductance (HQVC) were calculated by dividing the Doppler shift $(\mathrm{Hz})$ by MAP $(\mathrm{mmHg})$. The maximal percent changes in MBF, HQBF, MVC, HQVC and the area under the curve (AUC) for the total change in MVC and HVC were expressed as a percentage of control. Results are presented as means \pm SEM. The data were analyzed by one-way analysis of variance followed by the Fisher LSD test. A value of $p<0.05$ was considered to denote a significant difference.

\section{RESULTS}

Cardiovascular adjustments induced by hypothalamic stimulation (HS). In intact anesthetized rats electrical stimulation of the ventral perifornical region of the hypothalamus (Figure 2) elicited a pattern of cardiovascular adjustments characterized by hypertension, tachycardia, increase in hindquarter blood flow (HQBF) and decrease in mesenteric blood flow (MBF) (Figure 2A). MAP and HR responses had a latency of 2 to $3 \mathrm{~s}$, peaked after $6 \mathrm{~s}$ and returned gradually to basal levels after the end of the stimulation period. Blood flow responses had a longer latency ( 6 to $8 \mathrm{~s}$ ) and a much longer duration, remaining elevated up to $60 \mathrm{~s}$ after the onset of stimulation. The hindquarter and mesenteric vascular conductances (HQVC and MVC, respectively) were calculated as the blood flow/MAP ratio and expressed as percent of baseline. As shown in Figure 3A, HS was associated with a marked, long-lasting increase in HQVC indicating active vasodilation. On the other hand, a marked reduction of MVC was observed, indicating visceral vasoconstriction (Figure 3B). Resting levels and maximal changes during $\mathrm{HS}$ for all variables are presented in Table I.

Effects of $\alpha$-Adrenoceptor blockade and bilateral adrenalectomy on cardiovascular adjustments to HS. According to Yardley and Hilton (Yardley and 
TABLE I

Effects of phentolamine, bilateral adrenalectomy and L-NAME on the cardiovascular responses to hypothalamic stimulation (HS).

\begin{tabular}{|c|c|c|c|c|c|c|c|c|c|}
\hline \multirow[b]{2}{*}{ MAP } & \multicolumn{3}{|c|}{ CONTROL } & \multicolumn{3}{|c|}{ PHENT+ADREN } & \multicolumn{3}{|c|}{$\begin{array}{c}\text { PHENT+ADREN } \\
\text { +L-NAME }\end{array}$} \\
\hline & & & & & & & & & \\
\hline Basal (mmHg) & 110 & \pm & 2.9 & 94 & \pm & $4.6^{\mathrm{a}}$ & 119 & \pm & $1.5^{\mathrm{ab}}$ \\
\hline $\mathrm{HS}(\Delta, \mathrm{mmHg})$ & 32 & \pm & 3.4 & 33 & \pm & 2.1 & 30 & \pm & 5 \\
\hline \multicolumn{10}{|l|}{ HR } \\
\hline Basal (beats/min) & 351 & \pm & 11.4 & 360 & \pm & $11.2^{\mathrm{a}}$ & 292 & \pm & $8.9^{\mathbf{a b}}$ \\
\hline $\operatorname{HS}(\Delta$, beats/min $)$ & 36 & \pm & 5.6 & 48 & \pm & 9.7 & 32 & \pm & $7.5^{\mathbf{b}}$ \\
\hline \multicolumn{10}{|l|}{ MBF } \\
\hline Basal (Hz) & 6086 & \pm & 554 & 4679 & \pm & $439^{a}$ & 3848 & \pm & $333^{\mathbf{a b}}$ \\
\hline HS ( $\%$ of control) & -52 & \pm & 2.6 & -26 & \pm & $5.3^{\mathrm{a}}$ & -19 & \pm & $6^{\mathbf{a b}}$ \\
\hline \multicolumn{10}{|l|}{ MVC } \\
\hline Basal (Hz/mmHg) & 55 & \pm & 4.3 & 50 & \pm & 4.3 & 32 & \pm & $3^{\mathbf{a b}}$ \\
\hline HS ( $\%$ of control) & -50 & \pm & 3.5 & -44 & \pm & 4.9 & -31 & \pm & $6.1^{\mathrm{ab}}$ \\
\hline HS (\% AUC) & \multicolumn{3}{|c|}{100} & 77 & \pm & 15.8 & 31 & \pm & $8.4^{\mathbf{b}}$ \\
\hline \multicolumn{10}{|l|}{ HQBF } \\
\hline Basal (Hz) & 3061 & \pm & 243 & 2835 & \pm & 231 & 1614 & \pm & $165^{\mathrm{ab}}$ \\
\hline HS (\% of control) & 132 & \pm & 10.7 & 66 & \pm & $7.4^{\mathrm{a}}$ & 34 & \pm & $5.2^{\mathbf{a b}}$ \\
\hline \multicolumn{10}{|l|}{ HQVC } \\
\hline Basal (Hz/mmHg) & 28 & \pm & 2.3 & 31 & \pm & 3.1 & 14 & \pm & $1.4^{\mathbf{a b}}$ \\
\hline HS ( $\%$ of control) & 169 & \pm & 13 & 45 & \pm & $9.4^{\mathbf{a}}$ & 16 & \pm & $4.2^{\mathbf{a b}}$ \\
\hline HS (\% AUC) & \multicolumn{3}{|c|}{100} & 12 & \pm & 2.8 & 3 & \pm & $1^{b}$ \\
\hline
\end{tabular}

Values are means $\pm S E M ; n=8$. Comparisons of effects of HS on mean arterial pressure (MAP), heart rate (HR), mesenteric blood flow (MBF), mesenteric vascular conductance (MVC), hind limbs blood flow (HQBF), hind limbs vascular conductance (HQVC) before (Control) and after phentolamine $(1.5 \mathrm{mg} / \mathrm{kg}$, iv) plus bilateral adrenalectomy and after phentolamine plus bilateral adrenalectomy plus L-NAME (20mg/kg, iv). ${ }^{\mathbf{a}} p<0.05$ compared to control, b $p<0.05$ compared to PHENT+ADREN. 


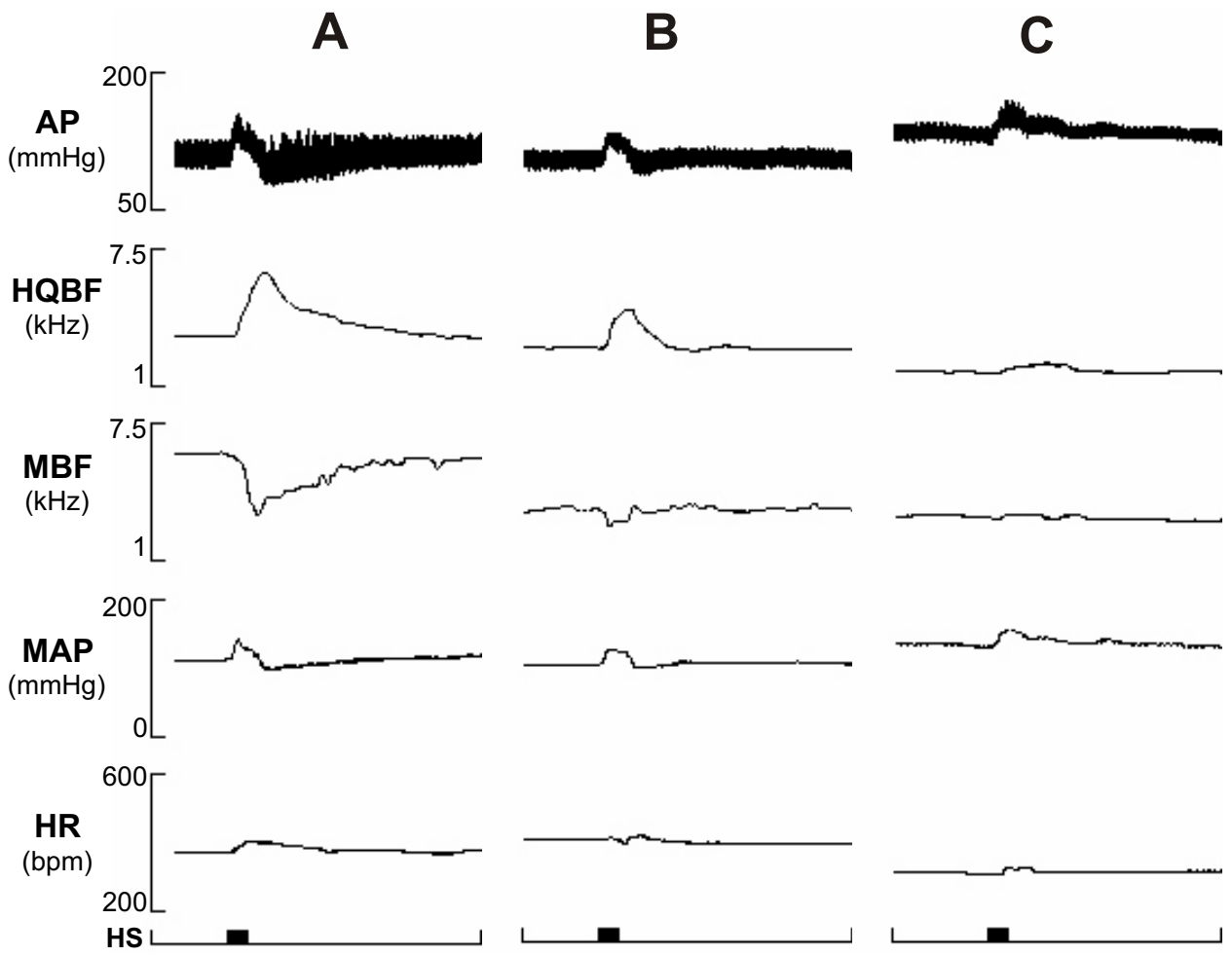

Fig. 2 - Changes in pulsatile arterial pressure (AP), hindquarter blood flow (HQBF); mesenteric blood flow (MBF), mean arterial pressure (MAP) and heart rate (HR) produced by hypothalamic stimulation (HS) ( $6 \mathrm{~s}$ trains, $1 \mathrm{~ms}$ square pulses, $100 \mathrm{~Hz}, 150 \mu \mathrm{A}$ ), before (A) and after phentolamine (1.5 mg/kg, iv) plus bilateral adrenalectomy (B) and after phentolamine plus bilateral adrenalectomy plus L-NAME (20 mg/kg, iv) (C). Horizontal bars represent the 6- $s$ trains of electrical stimulation.

Hilton 1986, 1987), the muscle vasodilation produced by electrical stimulation of the hypothalamus in rats is due to a combination of reduction of the sympathetic vasoconstrictor tone and activation of $\beta 2$-adrenergic receptors by catecholamines release. In the present study, after the cardiovascular adjustments to HS had been established, the animals received the $\alpha$-receptor antagonist phentolamine $(1.5 \mathrm{mg} / \mathrm{kg}$, iv) and both adrenal glands were removed. As shown in Figure 2B, 30 min after phentolamine plus bilateral adrenalectomy MAP, MBF and HQBF were reduced, while HR increased discretely. In this condition pressor and tachycardic responses to HS were unaffected. Conversely, marked reductions in the magnitude and duration of HBF and MBF responses were observed. Therefore, the magnitude and duration of the mesen- teric vasoconstriction and the hindquarter vasodilation were also reduced (Figure 3). However, it is noteworthy that although a strong reduction of the control response was observed the remaining vasodilation was substantial, consisting of an increase in HQVC of $50 \%$ at its peak and $25 \mathrm{~s}$ of duration (Figure 3A). The results obtained in this group of experiments are summarized in Table I. Pressor and tachycardic responses to HS after phentolamine + adrenalectomy were similar to those observed in the control. Maximal changes in MBF, HQBF and HQVC were strongly reduced. When blood flow adjustments to HS were evaluated by the area of the vascular conductance curves, a marked reduction in hindquarter vasodilation was observed. Indeed, after phentolamine + adrenalectomy, the area under the HQVC curve was reduced to $12 \%$ of that ob- 

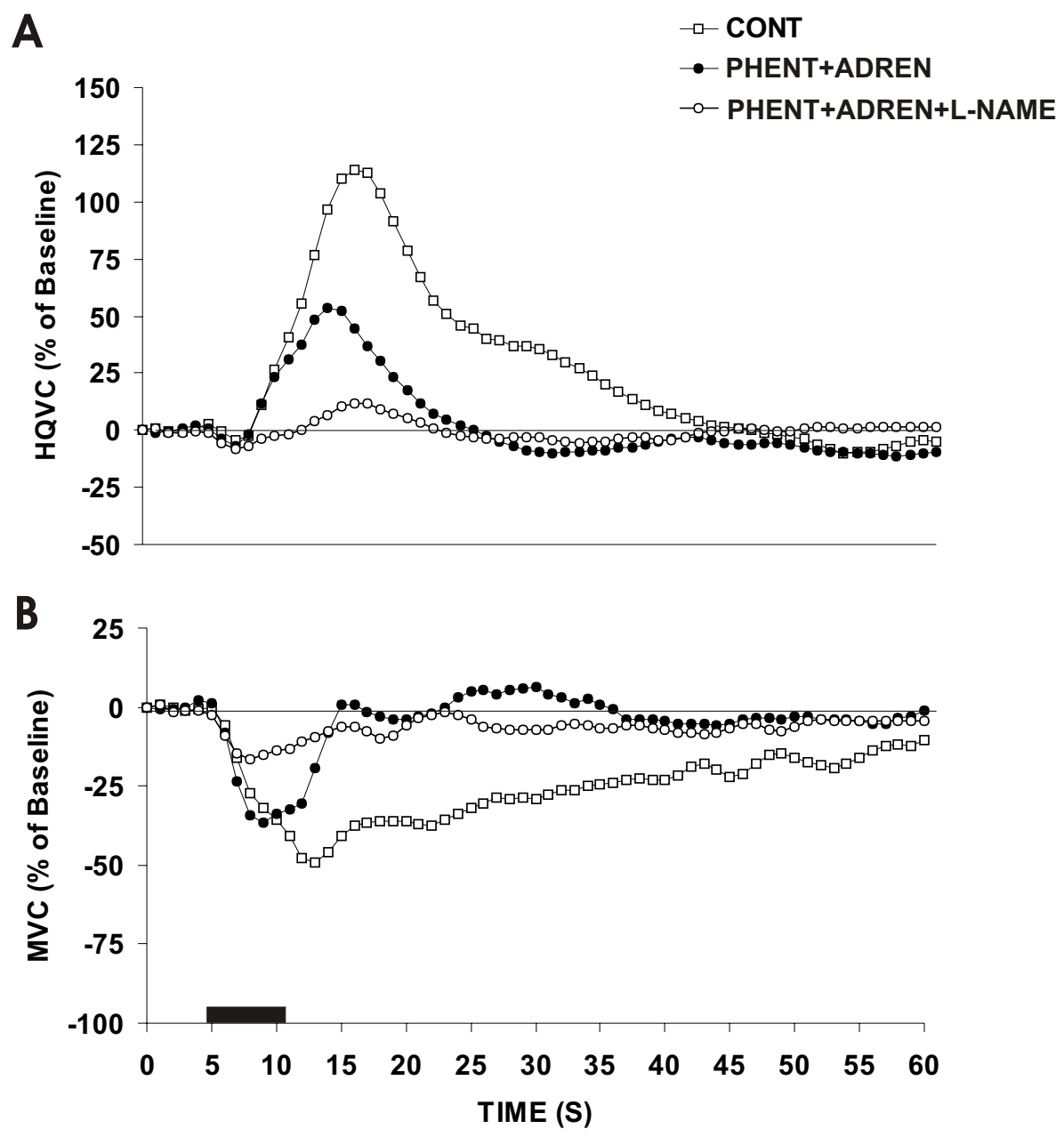

Fig. 3 - Effects of HS on hindquarter vascular conductance (HQVC \% of baseline) (A) and mesenteric vascular conductance (MVC \% of baseline) (B) before (square) and after phentolamine $(1.5 \mathrm{mg} / \mathrm{kg}$, iv) plus bilateral adrenalectomy (PHENT+ADREN) (filled circles) and after phentolamine plus bilateral adrenalectomy plus L-NAME (20 mg/kg, iv) (PHENT+ADREN+L-NAME) (open circles).

served during the control period. Mesenteric vasoconstriction to HS was also reduced after phentolamine + adrenalectomy though to a lesser extent.

\section{Effects of L-NAME on hemodynamic responses} produced by $\mathrm{HS}$ in adrenalectomized animals with $\alpha$-adrenoceptor blockade. As previously described, the combination of $\alpha$-adrenoceptor blockade and bilateral adrenalectomy failed to abolish muscle vasodilation induced by HS. These observations suggest that, besides the reduction of sympathetic tone and the catecholamine release from adrenal glands, another mechanism must participate in this vasodilatory response. To test this hypothesis, after phentolamine and bilateral removal of the adrenal glands animals were treated with the NO synthesis inhibitor L-NAME (20 mg/kg, iv). As shown in Figure 2C, after L-NAME pulsatile arterial pressure and MAP increased whereas basal HR, HQBF and MBF levels were reduced. Pressor and tachycardic responses to HS were not affected. However, changes in HQBF and MBF were severely reduced. Vascular conductance curves indicate that after L-NAME hindquarter vasodilation was reduced to a residual response whose onset was no longer locked to HS (Figure 3A). Similarly, 
mesenteric vasoconstriction was greatly reduced in magnitude and duration. The results obtained after L-NAME in this group of experiments are summarized in Table I.

Effects of L-NAME on the hemodynamic responses produced by HS. The results obtained in the previous group of experiments suggest that release of NO may be a component of the muscle vasodilation produced by HS. However, since in those animals the muscle vasodilation had already been greatly reduced by the combination of phentolamine plus adrenalectomy, the magnitude of the NO mechanism could not be properly evaluated. To determine the role played by NO in these responses we examined the cardiovascular adjustments to HS before and after systemic administration of LNAME (20 mg/kg iv). As previously described, in anesthetized rats HS produced hypertension, tachycardia, hindquarter vasodilation and mesenteric vasoconstriction (Figures 4A and 5). Thirty minutes after intravenous injection of L-NAME an increase in the basal MAP values was observed, whereas HR, MBF and HQBF were decreased (Fig 4B). The fall in $M B F$ and HQBF resting levels was associated with a decrease in vascular conductance in both territories. The HS elicited rises in MAP and HR that were similar to those observed during the control period. The HQBF response to HS was markedly reduced both in magnitude and duration. A distinct reduction in MBF was still observed also when compared to the control period.

L-NAME treatment reduced hindquarter vasodilation in magnitude and duration. As shown in Figure 5A, after L-NAME the peak of HQVC was reduced to approximately $50 \%$ and duration was reduced to less than $20 \mathrm{~s}$. After L-NAME this vasodilatory response was often followed by a long period of reduced vascular conductance as depicted in Figure 5A. The mesenteric vasoconstriction induced by HS was not affected.

As shown in Table II, the intravenous injection of the L-NAME produced a rise in MAP resting levels while $\mathrm{HR}, \mathrm{MBF}, \mathrm{MVC}, \mathrm{HQBF}$ and $\mathrm{HQVC}$ were decreased. Pressor and tachycardic responses to HS were not modified. Reductions in MBF and MVC were not different from the control period. On the other hand, the increase in HQBF was diminished. Muscle vasodilation as indicated by the area under the HQVC curve was reduced to $8 \%$ of that observed during the control period.

Effects of $\alpha$-adrenoceptor blockade and adrenalectomy on hemodynamic responses produced by HS in animals with NO synthesis blockade. After intravenous injection of L-NAME and analysis of the cardiovascular adjustments to HS, the animals received phentolamine $(1.5 \mathrm{~g} / \mathrm{kg}$, iv $)$ and both adrenal glands were removed. In this condition blood pressure was reduced, while MBF was augmented. HS induced hypertension and tachycardia, but changes in HQBF and MBF were reduced (Figure 4C). These reductions resulted in a smaller hindquarter vasodilation and mesenteric vasoconstriction (Figure 5). The results obtained in these experiments are summarized in Table II.

\section{DISCUSSION}

The present results demonstrated that in anesthetized rats electrical stimulation of the hypothalamus elicited the already well described pattern of cardiovascular adjustments consisting of hypertension, tachycardia, visceral vasoconstriction and hindlimb vasodilation. Alpha-adrenergic blockade plus bilateral adrenalectomy reduced, but did not abolish, hindlimb vasodilation. The residual vasodilation was completely abolished after blockade of NO synthesis by L-NAME. Similarly, when LNAME was administered to anesthetized animals, vasodilation induced by hypothalamic stimulation was profoundly reduced and the remaining response was abolished by the combination of adrenergic blockade plus adrenalectomy.

Histological analysis demonstrated that the stimulation sites in this study were consistently found in the perifornical area in the lateral hypothalamus. These sites are inside the area previously described by others as the hypothalamic defense 
TABLE II

Effects of L-NAME, phentolamine and bilateral adrenalectomy on the cardiovascular responses to hypothalamic stimulation (HS).

\begin{tabular}{|c|c|c|c|c|c|c|c|c|c|}
\hline \multirow[b]{2}{*}{ MAP } & \multicolumn{3}{|c|}{ CONTROL } & \multicolumn{3}{|c|}{ L-NAME } & \multicolumn{3}{|c|}{$\begin{array}{c}\text { L-NAME+PHENT } \\
\text { +ADREN }\end{array}$} \\
\hline & & & & & & & & & \\
\hline Basal (mmHg) & 109 & \pm & 2.9 & 134 & \pm & $4.5^{\mathrm{a}}$ & 108 & \pm & $7.7^{\mathbf{b}}$ \\
\hline $\mathrm{HS}(\Delta, \mathrm{mmHg})$ & 40 & \pm & 3.1 & 31 & \pm & 3.5 & 36 & \pm & 5.3 \\
\hline \multicolumn{10}{|l|}{ HR } \\
\hline Basal (beats/min) & 335 & \pm & 16 & 276 & \pm & $20^{\mathbf{a}}$ & 319 & \pm & $27.1^{\mathrm{a}}$ \\
\hline $\operatorname{HS}(\Delta$, beats/min $)$ & 37 & \pm & 4.5 & 37 & \pm & 10.2 & 53 & \pm & 6.5 \\
\hline \multicolumn{10}{|l|}{ MBF } \\
\hline Basal (Hz) & 7408 & \pm & 712 & 4679 & \pm & $551^{\mathrm{a}}$ & 4769 & \pm & $686^{\mathbf{a}}$ \\
\hline HS ( $\%$ of control) & -71 & \pm & 6.1 & -66 & \pm & 8.6 & -50 & \pm & $6.3^{\mathbf{a b}}$ \\
\hline \multicolumn{10}{|l|}{ MVC } \\
\hline Basal (Hz/mmHg) & 68 & \pm & 7.2 & 35 & \pm & $3.9^{\mathrm{a}}$ & 44 & \pm & $5.1^{\mathrm{a}}$ \\
\hline HS ( $\%$ of control) & -75 & \pm & 6.1 & -72 & \pm & 9 & -59 & \pm & $6.4^{\mathbf{a}}$ \\
\hline HS (\% AUC) & \multicolumn{3}{|c|}{100} & 87 & \pm & 11.7 & 39 & \pm & $10^{\mathbf{b}}$ \\
\hline \multicolumn{10}{|l|}{ HQBF } \\
\hline Basal (Hz) & 3800 & \pm & 199 & 1923 & \pm & $169^{a}$ & 1753 & \pm & $110^{\mathbf{a}}$ \\
\hline HS (\% of control) & 150 & \pm & 7 & 104 & \pm & $21.9^{\mathbf{a}}$ & 66 & \pm & $16^{\mathbf{a}}$ \\
\hline \multicolumn{10}{|l|}{ HQVC } \\
\hline Basal (Hz/mmHg) & 35 & \pm & 2.4 & 15 & \pm & $1.4^{\mathrm{a}}$ & 17 & \pm & $1.7^{\mathrm{a}}$ \\
\hline HS ( $\%$ of control) & 152 & \pm & 7.8 & 85 & \pm & $16.4^{\mathrm{a}}$ & 34 & \pm & $1.9^{\mathrm{a}}$ \\
\hline $\mathrm{HS}(\% \mathrm{AUC})$ & \multicolumn{3}{|c|}{100} & 8 & \pm & 2 & 3 & \pm & $1.4^{\mathrm{b}}$ \\
\hline
\end{tabular}

Values are means $\pm S E M ; n=8$. Comparisons of effects of HS on mean arterial pressure (MAP), heart rate (HR), mesenteric blood flow (MBF), mesenteric vascular conductance (MVC), hind limbs blood flow (HQBF), hind limbs vascular conductance (HQVC) before (Control), after L-NAME ( $20 \mathrm{mg} / \mathrm{kg}$, iv), and after L-NAME plus phentolamine plus bilateral adrenalectomy $\left(1.5 \mathrm{mg} / \mathrm{kg}\right.$, iv). ${ }^{\mathrm{a}} p<0.05$ compared to control, ${ }^{\mathbf{b}} p<0.05$ compared to L-NAME. 
A

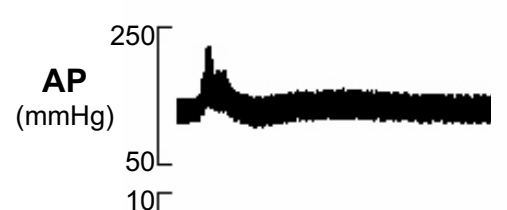

B

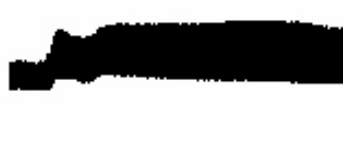

C
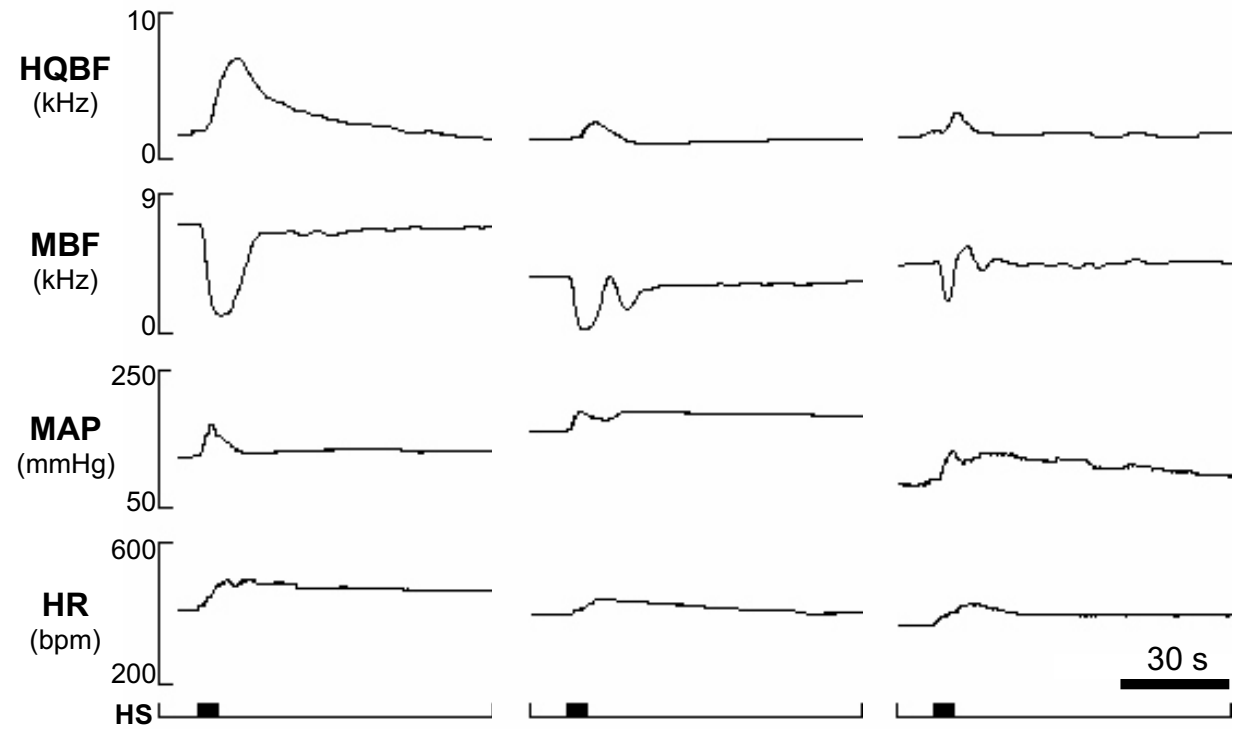

Fig. 4 - Changes in pulsatile arterial pressure (AP), hindquarter blood flow (HQBF), mesenteric blood flow (MBF), and mean arterial pressure (MAP) and heart rate (HR) produced by hypothalamic stimulation (HS) (6-s trains, $1 \mathrm{~ms}$ square pulses, $100 \mathrm{~Hz}, 150 \mu \mathrm{A}$ ), before (A), after L-NAME (20 mg/kg, iv) (B) and after L-NAME plus phentolamine $(1.5 \mathrm{mg} / \mathrm{kg}$, iv) plus bilateral adrenalectomy $(\mathrm{C})$. Horizontal bars represent the 6 -s trains of electrical stimulation.

area of the rat (Tan and Dampney 1983, Yardley and Hilton 1986, 1987).

The pattern of cardiovascular adjustments observed in the present study is also compatible with previously described data (Kiely and Gordon 1994, Yardley and Hilton 1987, Hilton and Zbrozyna 1963). This pattern is characterized by increases in arterial blood pressure and heart rate. Cardiac output is redistributed with distinctive decreases in the mesenteric vascular conductance and a marked, long-lasting increase in hindquarter vascular conductance. It is accepted that the reduction in mesenteric vascular conductance is representative of a general vasoconstriction in abdominal viscera, whereas the increase in hindquarter vascular conductance illustrates vasodilation of skeletal muscle present in the hind and forelimbs.

After adrenergic blockade plus bilateral adrenalectomy, a marked reduction in the magni- tude and particularly in the duration of the vasodilator response induced by hypothalamic stimulation was observed. This result is compatible with previous studies on anesthetized rats (Yardley and Hilton 1987). According to these authors, the hindlimb vasodilation induced by hypothalamic stimulation comprises at least two major components: an initial, short response, due to reduction of sympathetic vasoconstrictor tone, followed by a late, long-lasting response due to the release of catecholamines that act on $\beta_{2}$-adrenergic receptors in the vasculature of the skeletal muscle. It is noteworthy that adrenalectomy and phentolamine alone had little effect on the magnitude of the vasodilation. Bilateral adrenalectomy seemed to reduce preferentially the duration of the response whereas $\alpha$-adrenergic blockade tended to increase the latency of the response. Significant reductions of the response were obtained only after combined blockade of both components, 

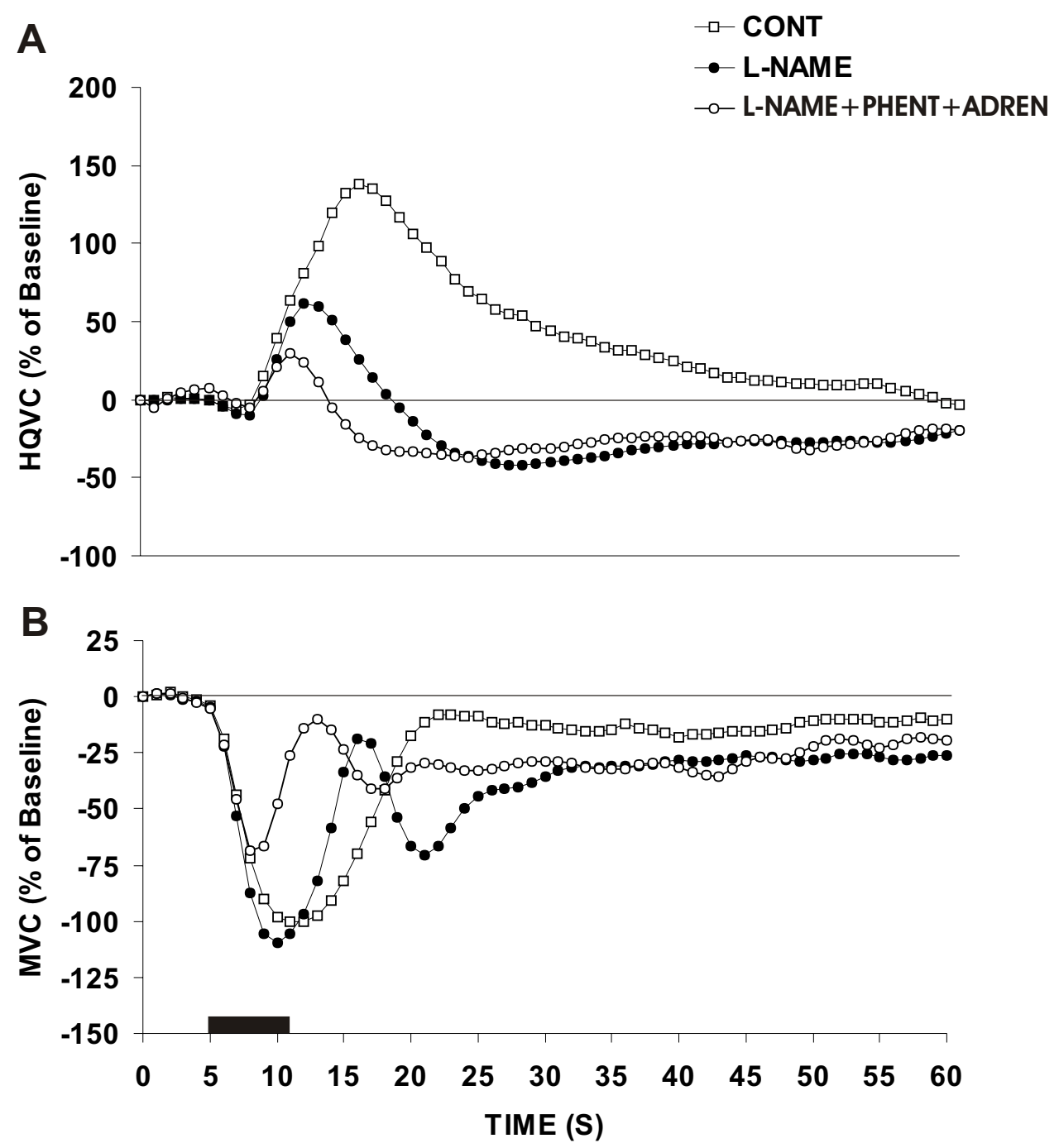

Fig. 5 - Effects of HS on hindquarter vascular conductance (HQVC \% of baseline) (A) and mesenteric vascular conductance (MVC \% of baseline) (B) before (square), after LNAME (20 mg/kg, iv) (filled circles) and after L-NAME plus phentolamine plus bilateral adrenalectomy (open circles).

no matter the sequence of procedures performed.

However, as described in this study, significant vasodilator response remains after treatment with phentolamine and adrenalectomy, suggesting the presence of a yet another vasodilator mechanism.

Curiously, the existence of a unidentified vasodilator mechanism during defense reactions in the rat has been acknowledge previously (Yardley and Hilton 1987), but it was thought that the two already described mechanisms account for the largest part of the observed hindlimb vasodilation.
Lewis and colleagues suggested that release of NO or NOFs may have contributed to defenserelated vasodilation. These investigators demonstrated that air-jet stress in conscious rats produces hindquarter vasodilation, which is markedly diminished by blockade of impulse propagation-mediated release of neurotransmitters or by inhibition of NO synthesis (Davisson et al. 1994). They also demonstrated that postganglionic lumbar sympathetic nerves innervating the hindlimb vasculature of the rat contain NOS and that low-intensity electrical 
stimulation of the lumbar sympathetic chain produces a pronounced hindlimb vasodilation, which is abolished by the administration of 7-nitroindazole (7-NI), a specific inhibitor of neuronal NOS. In addition, studies in cats demonstrated that forelimb and hindlimb vasodilation produced by hypothalamic stimulation were greatly attenuated by the inhibitor of nitric oxide synthesis, $N^{\omega}$-nitro-Larginine methyl ester (L-NAME) (Komine et al. 2003, Matsukawa et al. 1993).

The second component of vasodilation is more persistent, and is due to release of catecholamines into the circulation. Previous studies have suggested that relaxation of vascular smooth muscle induced by $\beta_{2}$ receptor activation may involve synthesis of NO and NO factors (Xu et al. 2000, Graves and Poston 1993, Gardiner et al. 1991). Previous studies have also suggested that circulating catecholamines may induce NO release by the endothelial cells through activation of $\alpha_{1}, \alpha_{2}$ and $\beta_{2}$ adrenergic receptors. Inhibition of NO synthesis by L-NAME would block this component. Alternatively, it is conceivable that reduction of the late stage vasodilation is due to a L-NAME-induced reduction of blood flow to the adrenal gland, resulting in a reduced transport of catecholamines from the adrenal medulla to its target tissues. The results obtained in the present study after inhibition of NO synthesis by L-NAME in animals pre-treated with phentolamine and submitted to bilateral adrenalectomy are compatible with the hypothesis that NO mediates part of the hindlimb vasodilation induced by hypothalamic stimulation.

To further confirm these observations, in a separate group of animals the order of blockade was inverted, and NO synthesis inhibition by L-NAME preceded bilateral adrenalectomy and adrenergic blockade. Surprisingly, L-NAME treatment resulted in a marked decrease in the magnitude and duration of the hindlimb vasodilation induced by hypothalamic stimulation. In fact, the area under the curve of vascular conductance after L-NAME was only $8 \%$ of that in control. This reduction was comparable to that produced by the combination of adrenergic blockade and adrenalectomy.

These results further support the hypothesis that NO release is a critical component of the hindlimb vasodilation induced by hypothalamic stimulation. However, the extent of the reduction in the vasodilator response after L-NAME demands further consideration. The observation that LNAME reduced vasodilation by as much as $90 \%$ of the control response suggests that, besides acting on a putative nitrergic system, inhibition of NO synthesis may also interfere with other vasodilator mechanisms.

The initial component of vasodilation is presumably due to a withdrawal of sympathetic vasoconstrictor drive. It is conceivable that the hypertension induced by L-NAME activated the baroreceptors, resulting in sympatho-inhibition. If sympathetic activity after L-NAME is low, it is not surprising that hypothalamic stimulation had little effect on this component.

The second component of vasodilation is more persistent, and is due to release of catecholamines into the circulation. Previous studies have suggested that relaxation of vascular smooth muscle induced by $\beta_{2}$ receptor activation may involve synthesis of NO and NO factors (Xu et al. 2000, Graves and Poston 1993, Gardiner et al. 1991). Previous studies have also suggested that circulating catecholamines may induce NO release by the endothelial cells through activation of $\alpha_{1}, \alpha_{2}$ and $\beta_{2}$ adrenergic receptors. Inhibition of NO synthesis by L-NAME would block this component. Alternatively, it is conceivable that reduction of the late stage vasodilation is due to a L-NAME-induced reduction of blood flow to the adrenal gland, resulting in a reduced transport of catecholamines from the adrenal medulla to its target tissues.

The results obtained in the present study suggest a prominent role of $\mathrm{NO}$ in the muscle vasodilation induced by stimulation of defense areas in the rat hypothalamus. Whether NO arises from neurotransmitters acting on endothelium cells or from specific sympathetic post-ganglionic fibers remains to be determined. 


\section{ACKNOWLEDGMENTS}

This work was supported by Fundação de Amparo à Pesquisa do Estado de São Paulo (FAPESP), Grants: 01/3391-3; 98/06231-2; 99/00735-1 and Conselho Nacional de Desenvolvimento Científico e Tecnológico, Porgrama de Apoio a Núcleos de Excelência (PRONEX/CNPq ), Grant: 66.1065/1998/7. Authors are grateful to Dr. Guus Schoorlemmer for reviewing the manuscript.

\section{RESUMO}

Em animais anestesiados a EE do hipotálamo produz um padrão de ajustes cardiovasculares caracterizado por hipertensão arterial, taquicardia, vasodilatação muscular e vasoconstrição mesentérica, entretanto, os mecanismos periféricos envolvidos nestes ajustes cardiovasculares ainda não foram completamente esclarecidos. O presente estudo teve como objetivo caracterizar os mecanismos periféricos responsáveis pela redistribuição de fluxo sanguíneo produzidas pela EE do hipotálamo. Os resultados obtidos demonstraram que 1) em ratos anestesiados a EE do hipotálamo produziu hipertensão arterial, taquicardia, vasoconstrição no leito mesentérico e acentuada vasodilatação dos membros posteriores; 2) a combinação do bloqueio farmacológico de receptores $\alpha_{1}$ e $\alpha_{2}$ adrenérgicos com fentolamina mais adrenalectomia bilateral reduziu a vasoconstrição mesentérica e a vasodilatação dos membros posteriores. Nestes animais o bloqueio da síntese de NO com L-NAME provocou nova redução significante da vasodilatação dos membros posteriores; 3) a administração de L-NAME, previamente o bloqueio farmacológico com fentolamina mais adrenalectomia bilateral, reduziu as respostas de vasoconstrição mesentérica e de vasodilatação dos membros posteriores. Estes resultados sugerem a existência de pelo menos três possíveis mecanismos responsáveis pela vasodilatação dos membros posteriores induzida pela EE do hipotálamo: 1) ativação de receptores $\beta$-adrenérgicos por catecolaminas liberadas pela medula adrenal; 2) redução do tono vasoconstritor simpático e 3) um terceiro mecanismo que utiliza NO como mediador.

Palavras-chave: fluxo sangüíneo dos membros posteriores, hipotálamo, estimulação elétrica, reação de defesa.

\section{REFERENCES}

Abrahams VC, Hilton SM and Zbrozyna AW. 1960a. Active muscle vasodilation produced by stimulation of the brainstem: its significance in the defence reaction. J Physiol 154: 491-513.

Abrahams VC, Hilton SM and Zbrozyna AW. 1960b. Reflex activation of vasodilator nerve fibres to skeletal muscle in decerebrate and intact cats. J Physiol 152: 54-55.

Abrahams VC, Hilton SM and Zbrozyna AW. 1964. The role of active muscle vasodilatation in the alerting stage of the defense reaction. J Physiol 171: 189202.

Azevedo AD, Hilton SM And Timms RJ. 1980. The defence reaction elicited by midbrain and hypothalamic stimulation in the rabbit. J Physiol 301: 56-57.

Bolme P, Ngai SH, Uvnäs B and Wallenberg LR. 1967. Circulatory and behavioural effects on electrical stimulation of the sympathetic vasodilator areas in the hypothalamus and mesencephalon in unanaesthetized dogs. Acta physiol scand 70: 334-346.

DAVISSON RL, Johnson AK AND LewIS SJ. 1994. Nitrosyl factors mediate active neurogenic hindquarter vasodilation in the conscious rat. Hypert 23: 962966.

Davisson RL, Possas OS, Murphy SP and Lewis SJ. 1997. Neurogenically-derived nitrosyl factors mediate lumbar sympathetic vasodilatation in the hindlimb vasculature of the rat. Am J Physiol 272: H2369-H2376.

Elliasson S, Folkow B, Lindgren O ANd UvNäs B. 1951. Activation of sympathetic vasodilator nerves to the skeletal muscles in the cat by hypothalamic stimulation. Acta physiol scand 23: 333-351.

Feigl E, Johansson B And Lofving B. 1964. Renal vasoconstriction and the defense reaction. Acta Physiol Scand 63: 429-435.

GARDiner SM, Kemp PA And Bennet T. 1991. Effects of $\mathrm{N}^{\mathrm{G}}$-nitro-L-arginine methyl ester on vasodilator responses to acetylcholine. 5'-N-ethylcarboxamidoadenosine or salbutamol in conscious rats. Br J Pharmacol, p. 1725-1732.

Graves J And Poston L. 1993. Beta-Adrenoceptor agonist mediated relaxation of rat isolated resistance arteries: a role for the endothelium and nitric oxide. Br J Pharmacol 108: 631-637. 
HAYwOOd JR, SHAFFER RA, FASTENOW C, FINK GD AND Brody MJ. 1981. Regional blood flow measurement with pulsed Doppler flowmeter in conscious rat. Am J Physiol 241: H273-H278.

Hilton SM And Zbrozyna AW. 1963. Amygdaloid region for defence reactions and its efferent pathway to the brainstem. J Physiol 165: 160-173.

KIELY JM AND GoRdon FJ. 1994. Role of rostral ventrolateral medulla in centrally mediated pressor responses. Am J Physiol 267: H1549-H1556.

Komine H, Matsukawa K, Murata J, Tsuchimochi T AND Shimizu K. 2003. Forelimb vasodilatation induced by hypothalamic stimulation is greatly mediated with nitric oxide in anesthetized cats. Jpn J Physiol 53: 97-103.

Matsukawa K, Shindo T, Shirai M and Ninomiya I. 1993. Nitric oxide mediates cat hindlimb cholinergic vasodilatation induced by stimulation of posterior hypothalamus. Jpn J Physiol 43: 473-483.

Paxinos G and Watson C. 1986. The Rat Brain in Stereotaxic Coordinates. Academic Press, Sydney.

Possas OS AND LEWIS SJ. 1997. NO-containing factors mediate hindlimb vasodilation produced by superior laryngeal nerve stimulation. Am J Physiol 273: $\mathrm{H} 234-\mathrm{H} 243$.

Quintin L, Gillon JY, Saunier CF, Chouvet G And Ghignone M. 1989. Continous volume infusion improves circulatory stability in anesthtized rat. J Neurosci Methods 30: 77-83.
Schramm LP, Honig CR and Bignall KE. 1971. Active muscle vasodilation in primates homologous with sympathetic vasodilation in carnivores. Am J Physiol 221: 768-777.

SMITH EM AND WoodrufF RA. 1980. Fear bradycardia in free-ranging woodchucks, Marmota monax. J Mamm 61: 750-753.

TAN E AND DAmpney RA. 1983. Cardiovascular effects of stimulation of neurones within the 'defence area' of the hypothalamus and midbrain of the rabbit. Clin Exp Pharmacol Physiol 10: 299-303.

Timms RJ. 1981. A study of the amygdaloid defence reaction showing the value of althesin anaesthesia in studies of the functions of the forebrain in cats. Pflugers Arch 391: 49-56.

Xu B, Li J, Gao L and Ferro A. 2000. Nitric oxidedependent vasodilatation of rabbit femoral artery by $\beta_{2}$-adrenergic stimulation or cyclic AMP elevation in vivo. Br J Pharmac 129: 969-974.

YARDLEy CP AND Hilton SM. 1986. The hypothalamus and brainstem areas from which the cardiovascular and behavioral components of the defence reaction are elicited in the rat. J Auton Nerv Syst 15: $227-$ 244.

YARDLEY CP AND HILTON SM. 1987. Vasodilatation in hind-limb skeletal muscle evoked as part of the defence reaction in the rat. J Auton Nerv Syst 19: 127-136. 